\title{
Characterization of Amperometric Biosensor in Cyclic Voltametry
}

\author{
K. KalyanBabu \\ Asst.Professor, \\ Gitam University
}

\begin{abstract}
In this paper, I would like to present basic characterization of Electro Chemical Biosensor. Biosensors are versatile, they are Amperometric and Immuno biosensors. In this paper the cyclic voltametry technique is used to detect the pathogens in analyte. The resultant graph is between voltage and current.The amperometric biosensor gives current as output which judges the pathogen present in analyte. Biosensors with enzyme and product are used to detect the cancer cell. Biosensors with potassium ferrocynade along with $\mathrm{Nacl}$ is used to detect the cancer cell and the solution acts as electrolyte.
\end{abstract}

\section{Keywords}

Amperometric biosensor, cancer.

\section{INTRODUCTION}

Biosensors are invented in 1962 by MICHEAL CLARKE. It consists of 3 terminals. They are counter electrode, working electrode and reference electrode. The working electrode is $\mathrm{AU}$, reference electrode is $\mathrm{Ag}, \mathrm{Agcl}$ and counter electrode is made of platinum. The biosensor is made of evacuation glass with 4 openings. 3 for electrodes and remaining one is for analyte. Analyte means analysis to be taken out. The analyte is pathogenic blood. The biosensor is simply electro chemical cell made of glass.

\section{EXPERIMENTAL SETUP}

The below diagram shows the experimental setup of characterization of biosensor. The working electrode is made of Gold usually in red color. The counter electrode is platinum made of blue color. The reference electrode is made of white color .The electrodes are dipped in electrolyte where it is called BULK solution. The bare AU which is not modified by any solute is tested first .For that it is kept in FERROFERRI solution. The electrodes are kept in ferroferri solution and connected to SPECIAL SOFTWARE called ELECTRO COMM. The output voltage range may be $60 \mathrm{mv}$ to $90 \mathrm{mv}$. If we get the rated voltage then the biosensor is ready for experimentation.

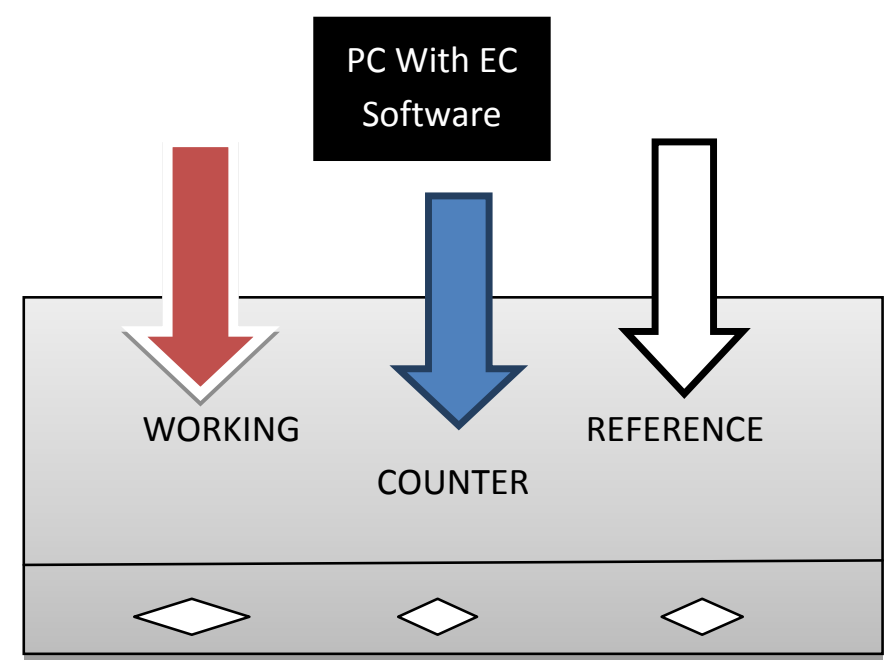

Fig 1

I

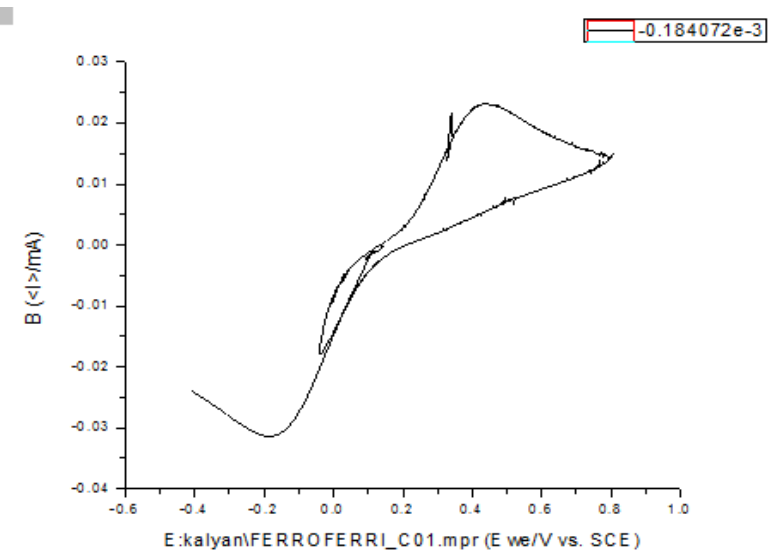

The above Figure1 represents the initial working of electro chemical biosensor. The biosensor with 3 electrodes initially tested with bare GLASSY CARBON electrode in the place of working electrode and tested with electro com software. The current decreases initially and later increases, goes to maximum peak and then decreases forming redox procedure. Now the biosensor is ready for testing the analytes. The BARE GC is removed and every electrode is made ready for experimentation.

\subsection{Lab Procedure 1}

Step1: Connect the cell to PC with electro com software and click on key to modify the voltage range. Generally it may be from $-0.2 \mathrm{v}$ to $0.8 \mathrm{v}$. The scan rate may be from $10 \mathrm{mv} / \mathrm{sec}$ to $90 \mathrm{mv} / \mathrm{sec}$. Click on RUN. This runs the software resulting in formation of voltammamogram. The voltammamogram is consisting of oxidation and reduction process cycles. Ei is starting potential $\mathrm{dE} / \mathrm{dt}$ is scan rate expressed in $\mathrm{mv} / \mathrm{second}$ The potential is with respect to reference, this doesn't change. 
Step2:Let us take $1 \mathrm{~mm}$ potassium ferrocynade in $0.1 \mathrm{~m}$ $\mathrm{Nacl}$ in $25 \mathrm{ml} \mathrm{H2O}$.Molecular weight $\mathrm{t}$ ofK4Fe (CN6) is 368.35.

$1 \mathrm{~mm}$ Molecule

$\mathrm{k} 4[\mathrm{Fe}(\mathrm{CN}) 6]=368.35 * 25 * 0.001 / 1000=0.0092 \mathrm{gms}$.

$0.1 \mathrm{~m}$ Nacl $=58.45 * 25 * 0.1 / 1000=0.146 \mathrm{gms}$.

\begin{tabular}{|c|c|c|}
\hline $\begin{array}{c}\text { Readings:FIXE } \\
\text { D SCAN } \\
\text { RATE: } \\
50 \mathrm{mv} / \mathrm{sec}\end{array}$ & Oxidation & Reduction \\
\hline Cycle1 & $\mathrm{I}=29.90 \mathrm{ua}, \mathrm{v}=270 \mathrm{mv}$ & $\begin{array}{c}\mathrm{I}=-23.30 \mathrm{ua} \\
\mathrm{v}=202 \mathrm{mv}\end{array}$ \\
\hline Cycle2 & $\begin{array}{c}I=26.90 \mathrm{ua}, \\
\mathrm{v}=268 \mathrm{mv}\end{array}$ & $\begin{array}{c}I=-- \\
24.20 u a, v=204 \mathrm{mv}\end{array}$ \\
\hline Cycle3 & $\begin{array}{c}I=28.40 \mathrm{ua}, \\
\mathrm{v}=266 \mathrm{mv}\end{array}$ & $\begin{array}{c}I=- \\
25.70 u a, v=200 \mathrm{mv}\end{array}$ \\
\hline Cycle4 & $\mathrm{I}=27.30 \mathrm{ua}, \mathrm{v}=270 \mathrm{mv}$ & $\begin{array}{c}I=- \\
26.2 \mathrm{ua}, \mathrm{v}=200 \mathrm{mv}\end{array}$ \\
\hline Cycle5 & $\mathrm{I}=26.80 \mathrm{ua}, \mathrm{v}=266 \mathrm{mv}$ & $\begin{array}{c}\mathrm{I}=- \\
26.3 \mathrm{ua}, \mathrm{v}=200 \mathrm{mv}\end{array}$ \\
\hline $\begin{array}{c}\text { Variable scan } \\
\text { rate }\end{array}$ & Oxidation & Reduction \\
\hline $5 \mathrm{mv} / \mathrm{sec}$ & $\begin{array}{c}\mathrm{I}=- \\
9.15 \mathrm{UA}, \mathrm{V}=274 \mathrm{MV}\end{array}$ & $\begin{array}{l}I=-5.79 \mathrm{UA} \\
V=192 \mathrm{MV}\end{array}$ \\
\hline 10MV/SEC & $\begin{array}{c}\mathrm{I}=12.46 \mathrm{UA}, \mathrm{V}=266 \\
\mathrm{MV}\end{array}$ & $\begin{array}{l}I=-9.66 \mathrm{UA} \\
\mathrm{V}=198 \mathrm{MV}\end{array}$ \\
\hline 20MV/SEC & $\begin{array}{c}\mathrm{I}=17.5 \mathrm{UAV} \\
\mathrm{V}\end{array}$ & $\begin{array}{c}\mathrm{I}=- \\
\text { 15.32UA, } \mathrm{V}=202 \mathrm{M} \\
\mathrm{V}\end{array}$ \\
\hline 30MV/SEC & $\begin{array}{c}\mathrm{I}=21.40 \mathrm{UA}, \mathrm{V}=264 \\
\mathrm{MV}\end{array}$ & $\begin{array}{c}I=- \\
19.5 \mathrm{UA}, \mathrm{V}=202 \mathrm{M} \\
\mathrm{V}\end{array}$ \\
\hline 40MV/SEC & $\underset{V}{\mathrm{I}=24.6 \mathrm{UA}, \mathrm{V}=264 \mathrm{M}}$ & $\begin{array}{c}\mathrm{I}=- \\
22.01 \mathrm{UA}, \mathrm{V}=198 \mathrm{M} \\
\mathrm{V}\end{array}$ \\
\hline 50MV/SEC & $\begin{array}{l}\mathrm{I}=27.6 \mathrm{UA}, \\
\mathrm{V}=272 \mathrm{MV}\end{array}$ & $\begin{array}{c}\mathrm{I}=- \\
\text { 37.70UA, }=198 \mathrm{M} \\
\mathrm{V}\end{array}$ \\
\hline 200MV/SEC & $\begin{array}{c}\mathrm{I}=54.90 \mathrm{UA}, \mathrm{V}=278 \\
\mathrm{MV}\end{array}$ & $\begin{array}{c}\mathrm{I}=- \\
\text { 53.90UA, } \mathrm{V}=190 \mathrm{M} \\
\mathrm{V}\end{array}$ \\
\hline 300MV/SEC & $\begin{array}{c}\mathrm{I}=67.10 \mathrm{UA}, \mathrm{V}=286 \\
\mathrm{MV}\end{array}$ & $\begin{array}{c}\mathrm{I}=-65.40 \mathrm{UA}, \\
\mathrm{V}=178 \mathrm{MV}\end{array}$ \\
\hline 400MV/SEC & $\begin{array}{c}\mathrm{I}=76.78 \mathrm{UA}, \\
\mathrm{V}=298 \mathrm{MV}\end{array}$ & $\begin{array}{c}I=-82.10 \mathrm{UA} \\
V=166 \mathrm{MV}\end{array}$ \\
\hline 500MV/SEC & 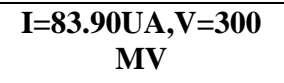 & \\
\hline
\end{tabular}

\subsection{Lab Procedure2:}

The above readings have obtained from the following procedure. The Electro com software is DOS based software.

a) Click on set up.

b) Next on new technique.

c) Next on DC current mode will display.

d) Click on cyclic voltammetry.

e) Set up file

f) Fix scan rate

g) Fix scan increment

h) Click on initial cycle

i) Click on filters

j) Then run the software.

k) Take the readings and plot them on ORIGIN software.

Before performing the experiment, the working electrode should be polished over a surface to make it clean. Then it is immersed on ferroferri solution and watch the characteristic.The resultant graph is as shown above ie figure1. It consists of Oxidation, reduction cycles with positive peak and negative peaks.

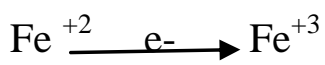

The above equation gives the illustration of Iron $(\mathrm{Fe})$ oxidizing to ferric oxide.

The bulk solution is $0.25 \mathrm{ml}$ of $\mathrm{H} 2 \mathrm{O}$ mixed with Ferro ferri solution.

The below diagram resembles the voltamamagram.

\section{E1}

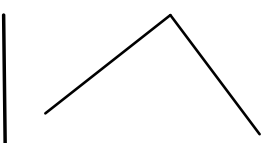

E0

E0

$$
\mathrm{t}
$$

Figure2

In the above figure2, $\mathrm{E}$ is found to be constant. It has same scan rate. It is found that at $1.2 \mathrm{v}$ aqueous solution starts its action. At 1.3 v $\mathrm{H} 20$ oxidizes and gives H202. At anodic position, oxygen occurs and at cathodic part, hydrogen occurs. 


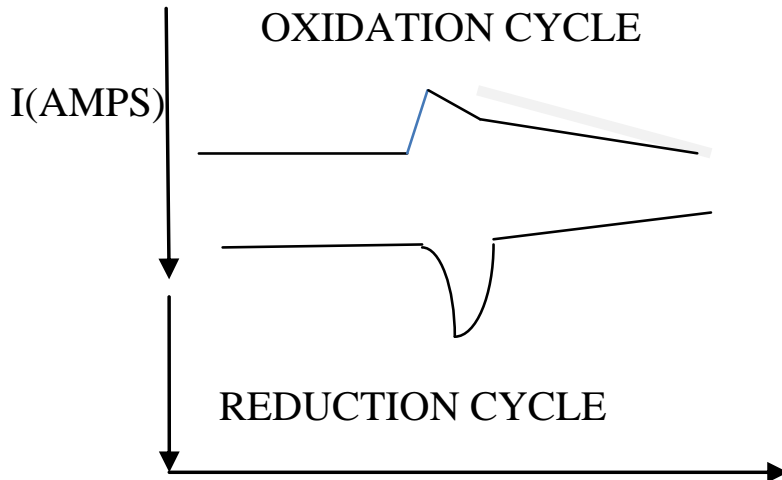

E(VOLTS)

Figure3

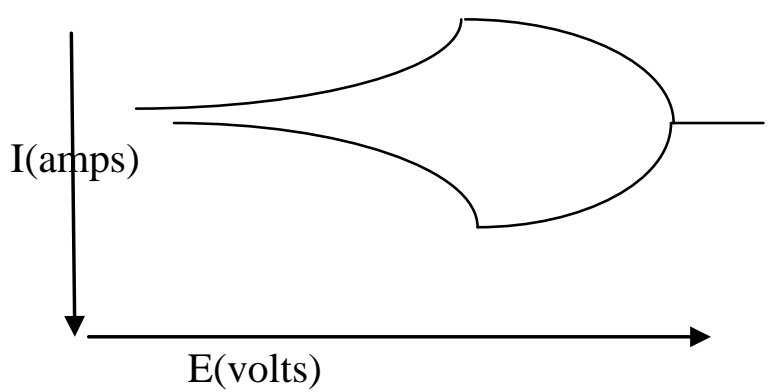

Figure4

The above figures 3 and 4 show the theoretical and practical graphs of cyclic voltammetry respectively.For positive cycle oxidation occurs and negative cycle reduction occurs. In theoretical concept, the graphs are very sharp, whereas in practical graphs are not as sharp as theoretical. For different scan rates the the experiment is carried out. The analyte is poured through 4 opening in biosensor cell and observe the oxidation and reduction peaks and cycles. The current transfer is done in the following way

By Migration, diffusion and convection. In diffusion process, concentration gradient occurs, where as in convection, heat and disturbances occur.

\section{MODELLING THE BIOSENSOR}

The modeling is presented by Michales and Menton standard equations given by

$$
\mathrm{E}+\mathrm{S} \rightarrow \rightarrow \rightarrow \rightarrow \mathrm{ESS}+\mathrm{P} .
$$

Where $\mathrm{E}$ stands for enzyme and $\mathrm{S}$ stands for substrate and ESS stands for Enzyme substrate complex and P stands for product.

\section{$\boldsymbol{\delta} \mathrm{E} / \boldsymbol{\delta} \mathrm{t}+\boldsymbol{\delta} \mathrm{S} / \boldsymbol{\delta} \mathrm{t} \boldsymbol{\longrightarrow} \rightarrow \partial \mathrm{ESS} / \boldsymbol{\delta} \mathrm{t}+\boldsymbol{\delta} \mathrm{p} / \boldsymbol{\delta} \mathrm{t}$}

The above equations resemble the mathematical modeling of biosensor with E as enzyme, S as Substrate, $\mathrm{P}$ as Product under ideal conditions.

The biosensor starts its action when substrate appears in bulk solution. Then the boundary condition is given by

$\mathrm{S}=0$ to $\mathrm{S}=\mathrm{P}$, then

$\boldsymbol{\delta} \mathrm{E} / \boldsymbol{\delta} \mathrm{t}+0=\boldsymbol{\delta} \mathrm{P} / \boldsymbol{\delta} \mathrm{t}$.P stands for product at initial condition.

\section{$\boldsymbol{\delta} \mathrm{E} / \boldsymbol{\delta} \mathrm{T}+\boldsymbol{\delta} \mathrm{P} / \boldsymbol{\delta} \mathrm{T}=\boldsymbol{\delta} \mathrm{ESS} / \boldsymbol{\delta} \mathrm{T}+\boldsymbol{\delta} \exp (2) \mathrm{P} / \boldsymbol{\delta} \operatorname{texp}(2)$}

The above equation is in final condition for the biosensor action at peak stage. The substrate can be conductor or semiconductor type, if it is conductor, metallic substrate is used. if it is semiconductor, silica substrate is used .Let us consider silica substrate with drain , source and gate. D is used for drain, $\mathrm{S}$ " for source and gate is denoted as $\mathrm{G}$.

The governing equations are given by

$\boldsymbol{\delta} \mathrm{D} / \boldsymbol{\delta} \mathrm{t}+\boldsymbol{\delta} \mathrm{S}{ }^{\prime} / \boldsymbol{\delta} \mathrm{t}=\boldsymbol{\delta} \mathrm{G} / \boldsymbol{\delta} \mathrm{t}$.

The above equation governs drain current and source current equal to gate current. Substrate allocation with drain source and gate in the Lower surface of the biosensor.

The working electrode resides on source, counter electrode resides on drain and reference electrode resides on gate electrolyte. The analyte is cancerous blood is poured into cell through $4^{\text {th }}$ opening of cell. The potassium ferrocynade with NACL bulk solution reacts with pathogenic blood and gives an output which is opposite to that of normal CYCLIC VOLTAMETRY. In normal CV, the oxidation and reduction peaks are clearly seen,but with analyte such as cancerous blood gives no oxidation and reduction of oxygen. The substrate which is FET device consisting of SOURCE, DRAIN and GATE, the output voltage reduces, because the cancer cell has less amount of GLUCOSE. Cancer cells are very flexible and they start loosing their grip on human body at the same rate of growth of cancer tumor.. Initially the cancer cell appears to be same as ordinary living cell, the characteristic is found to be same, but after an interval of 20 minutes say, the original characteristic comes with no redox potential.

\section{RESULTS AND DISCUSSION}

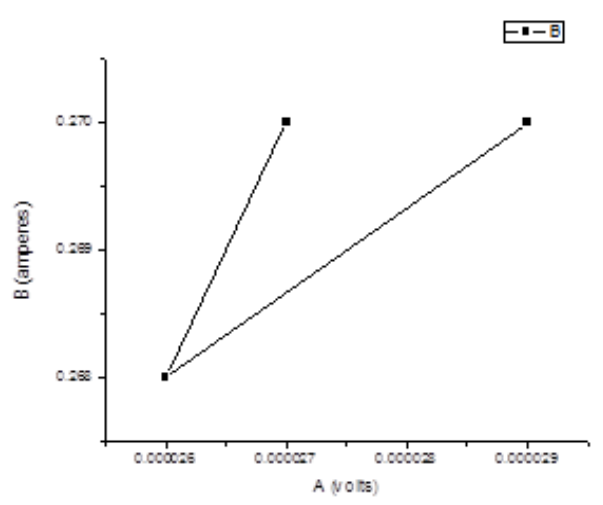

Fig ure5

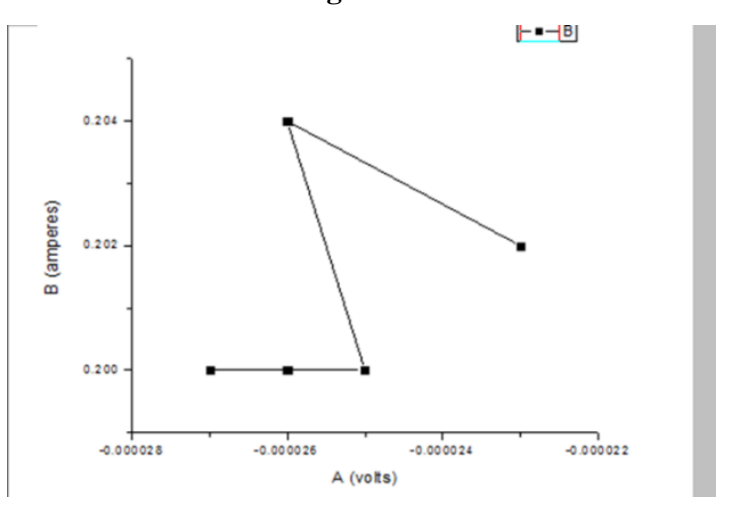

Figure6 
1

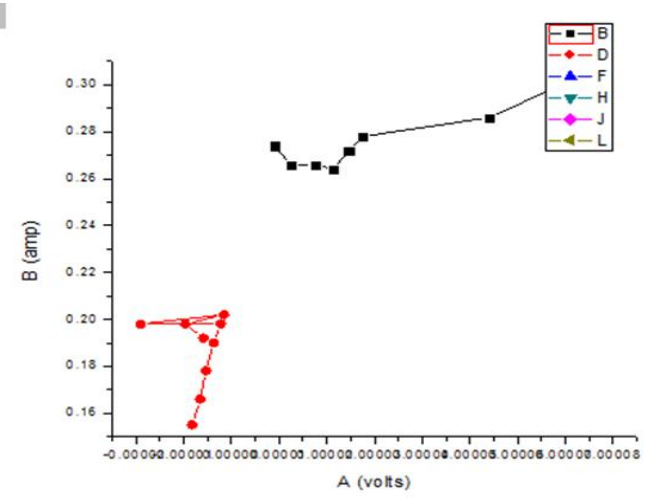

Figure7

The above figures 5,6,7 show the results of current over voltage in oxidation and reduction cycles for fixed scan rate and variable scan rate. The figure 7 is combined oxidation and reduction processes.

\section{CONCLUSION}

In this paper, I discussed the characterization of amperometric biosensor with cancerous blood samples with cyclic voltametry in oxidation and reduction cycles.

6. REFERENCES

[1] Simulations in NANO BIOTECHNOLOGY-KILHO EOM.

[2] Nano sensors-industry health care and defence-KimLim.

[3] Biosensors and cancer-Victor R Preedy Patel.

[4] Bhang HC, KCgabriel son-Tumor specific imaging.

[5] Brenner computed tomography.

[6] Dinca EB RB Voicu-brain tumours.

[7] O Brandid-peptide acids on micro arrays.

[8] Gao z Agarwal Label free cancer detection. 